\title{
Levosimendan for resuscitating the microcirculation in patients with septic shock: a randomized controlled study
}

\author{
Andrea Morelli ${ }^{*}$, Abele Donati ${ }^{2}$, Christian Ertmer ${ }^{3}$, Sebastian Rehberg ${ }^{3}$, Matthias Lange $^{3}$, Alessandra Orecchioni ${ }^{1}$, \\ Valeria Cecchini ${ }^{1}$, Giovanni Landoni ${ }^{4}$, Paolo Pelaia ${ }^{2}$, Paolo Pietropaoli', Hugo Van Aken ${ }^{3}$, Jean-Louis Teboul ${ }^{5}$, \\ Can Ince ${ }^{6,7}$, Martin Westphal ${ }^{3}$
}

\begin{abstract}
Introduction: The purpose of the present study was to investigate microcirculatory blood flow in patients with septic shock treated with levosimendan as compared to an active comparator drug (i.e. dobutamine). The primary end point was a difference of $\geq 20 \%$ in the microvascular flow index of small vessels (MFls) among groups.

Methods: The study was designed as a prospective, randomized, double-blind clinical trial and performed in a multidisciplinary intensive care unit. After achieving normovolemia and a mean arterial pressure of at least 65 $\mathrm{mmHg}, 40$ septic shock patients were randomized to receive either levosimendan $0.2 \mu \mathrm{gg} \cdot \mathrm{kg}^{-1} \cdot \mathrm{min}^{-1}(n=20)$ or an active comparator (dobutamine $5 \mu \mathrm{g} \cdot \mathrm{kg}^{-1} \cdot \mathrm{min}^{-1}$; control; $n=20$ ) for 24 hours. Sublingual microcirculatory blood flow of small and medium vessels was assessed by sidestream dark-field imaging. Microcirculatory variables and data from right heart catheterization were obtained at baseline and 24 hours after randomization. Baseline and demographic data were compared by means of Mann-Whitney rank sum test or chi-square test, as appropriate. Microvascular and hemodynamic variables were analyzed using the Mann-Whitney rank sum test.
\end{abstract}

Results: Microcirculatory flow indices of small and medium vessels increased over time and were significantly higher in the levosimendan group as compared to the control group (24 hrs: MFIm 3.0 (3.0; 3.0) vs. 2.9 (2.8; 3.0); $P=.02 ;$ MFIs $2.9(2.9 ; 3.0)$ vs. $2.7(2.3 ; 2.8) ; P<.001)$. The relative increase of perfused vessel density vs. baseline was significantly higher in the levosimendan group than in the control group (dMFIm $10(3 ; 23) \%$ vs. $0(-1 ; 9) \%$; $P=.007$; dMFIs $47(26 ; 83) \%$ vs. $10(-3 ; 27) ; P<.001)$. In addition, the heterogeneity index decreased only in the levosimendan group $(\mathrm{dHI}-93(-100 ;-84) \%$ vs. $0(-78 ; 57) \% ; P<.001)$. There was no statistically significant correlation between systemic and microcirculatory flow variables within each group (each $P>05$ ).

Conclusions: Compared to a standard dose of $5 \mu \mathrm{g} \cdot \mathrm{kg}^{-1} \cdot \mathrm{min}^{-1}$ of dobutamine, levosimendan at $0.2 \mu \mathrm{g} \cdot \mathrm{kg}^{-1} \cdot \mathrm{min}^{-1}$ improved sublingual microcirculatory blood flow in patients with septic shock, as reflected by changes in microcirculatory flow indices of small and medium vessels.

Trial registration: NCT00800306.

\section{Introduction}

Microvascular dysfunction plays a pivotal role in the pathophysiology of septic shock and may occur even in the presence of normal systemic oxygen supply and mean arterial pressure [1]. In this regard, several

\footnotetext{
* Correspondence: andrea.morelli@uniroma1.it

'Department of Anesthesiology and Intensive Care, University of Rome,

'La Sapienza', Viale del Policlinico 155, Rome 00161, Italy

Full list of author information is available at the end of the article
}

vasoactive agents, including inotropes, vasodilators, and inodilators, have been investigated in the attempt to preserve or improve microcirculatory blood flow in patients with severe sepsis or septic shock [1-5].

In recent years, much attention has been paid to the use of the calcium sensitizer levosimendan in the treatment of septic myocardial dysfunction [6-10]. Levosimendan increases myocardial contractility while simultaneously exerting vasodilatory properties via

\section{() Biomed Central}


activation of ATP-dependent potassium channels $\left(\mathrm{K}_{\mathrm{ATP}}\right)$ [11]. In addition, levosimendan exerts anti-ischemic, anti-inflammatory, and anti-apoptotic properties, thereby affecting important pathways in the pathophysiology of septic shock [12-14]. It has been speculated that, owing to these beneficial effects, levosimendan may positively affect myocardial performance and regional hemodynamics, thereby improving microcirculatory perfusion $[6-10,12,15,16]$.

The objective of the present randomized controlled, double-blinded clinical study was, therefore, to elucidate the effects of levosimendan on systemic and microvascular hemodynamics. On this basis, we aimed at rejecting the null hypothesis that there is no difference in sublingual microvascular blood flow - as measured by sidestream dark-field (SDF) imaging [17] - in patients with fluid-resuscitated septic shock treated with levosimendan as compared with an active comparator drug (that is, dobutamine).

\section{Materials and methods Patients}

After approval by the local institutional ethics committee, the study was performed in an 18-bed multidisciplinary intensive care unit (ICU) at the Department of Anesthesiology and Intensive Care of the University of Rome 'La Sapienza'. Informed consent was obtained from the patients' next of kin. Enrolment of patients started in January 2008 and ended in April 2009. We enrolled patients who fulfilled the criteria of septic shock that required norepinephrine (NE) to maintain a mean arterial pressure (MAP) of at least $65 \mathrm{~mm} \mathrm{Hg}$ despite appropriate volume resuscitation (pulmonary arterial occlusion pressure [PAOP] $=12$ to $18 \mathrm{~mm} \mathrm{Hg}$ and central venous pressure $[\mathrm{CVP}]=8$ to $12 \mathrm{~mm} \mathrm{Hg}$ ) [18]. Exclusion criteria of the study were age of less than 18 years, pregnancy, significant valvular heart disease, present or suspected acute coronary syndrome, and limitations to the use of inotropes (that is, ventricular outflow tract obstruction and mitral valve systolic anterior motion). All patients were sedated with sufentanil and midazolam and received mechanical ventilation using a volume-controlled mode.

\section{Hemodynamics, global oxygen transport, and acid-base balance}

Systemic hemodynamic monitoring of the patients included a pulmonary artery catheter (7.5-F; Edwards Lifesciences, Irvine, CA, USA) and a radial artery catheter. MAP, right atrial pressure, mean pulmonary arterial pressure, and PAOP were measured at end-expiration. Heart rate was analyzed from a continuous recording of electrocardiogram with ST segments monitored. Cardiac index (CI) was measured using the continuous thermodilution technique (Vigilance II; Edwards Lifesciences). Systemic vascular resistance index, pulmonary vascular resistance index, and left and right ventricular stroke work indices were calculated by means of standard equations. Arterial and mixed-venous blood samples were withdrawn to determine oxygen tensions and saturations as well as carbon dioxide tensions, standard bicarbonate, base excess, $\mathrm{pH}$, and lactate concentrations. $\mathrm{SvO}_{2}$ was measured discontinuously by intermittent mixed-venous blood gas analyses (Gem 4000 Premier; Instrumentation Laboratory Company, Bedford, MA, USA). Systemic oxygen delivery index $\left(\mathrm{DO}_{2} \mathrm{I}\right)$, oxygen consumption index, and oxygen extraction ratio were calculated by means of standard formulae.

\section{Microvascular network}

Microvascular blood flow was visualized by means of an SDF imaging device (MicroScan ${ }^{\mathbb{B}}$; MicroVision Medical, Amsterdam, The Netherlands) with a $5 \times$ magnification lens [17]. The optical probe was applied to the sublingual mucosa after gentle removal of saliva with a gauze swab. Three discrete fields were captured with precaution to minimize motion artifacts. Individual sequences of approximately 15 seconds were analyzed off-line with the aid of dedicated software (Automated Vascular Analysis 3.0; Academic Medical Center, University of Amsterdam, The Netherlands) in a randomized fashion by a single investigator who was unaware of the study protocol. Vessel density was automatically calculated from the software as the total vessel lengths of the small, medium, and large vessels, divided by the total area of the image [17]. The 'De Backer score' was calculated as described previously [17] and is based on the principle that density of the vessels is proportional to the number of vessels crossing arbitrary lines. In this score, three equidistant horizontal lines and three equidistant vertical lines are drawn on the screen, and then the De Backer score can be calculated as the number of small, medium, and large vessels crossing the lines, divided by the total length of the lines [17]. Vessel density was also calculated as the total vessel lengths divided by the total area of the image [17]. Both indices were automatically calculated by means of dedicated software (Automated Vascular Analysis 3.0). Perfusion was then categorized by eye as present (normal continuous flow for at least 15 seconds), sluggish (decreased but continuous flow for at least 15 seconds), absent (no flow for at least $50 \%$ of the time), or intermittent (no flow for less than $50 \%$ of the time) [17]. The proportion of perfused vessels (PPV) was calculated as follows: $100 \times$ [(total number of vessels - [no flow + intermittent flow])/total number of vessels]. Perfused vessel density (PVD) was calculated by multiplying vessel density by the proportion of perfused vessels [17]. 
Microvascular flow index [17] was used to quantify microvascular blood flow. In this score, flow is characterized as absent (0), intermittent (1), sluggish (2), or normal (3) [17]. Since our investigation was focused on small and medium vessels, calculations were performed separately for vessels with diameters of smaller than 20 $\mu \mathrm{m}$ (MFIs) and of larger than $20 \mu \mathrm{m}$ but smaller than $50 \mu \mathrm{m}$ (MFIm). Vessel size was determined with the aid of a micrometer scale. For each patient, values obtained from the three mucosa fields were averaged [17]. To assess flow heterogeneity between the different areas investigated, we used the heterogeneity index. The latter was calculated as the highest site flow velocity minus the lowest site flow velocity, divided by the mean flow velocity of all sublingual sites [17]. Percentage changes from baseline for all variables were determined as dVariable $=100 \times\left[\left(\right.\right.$ Value $_{24}$ hours $/$ Value $\left.\left._{\mathrm{BL}}\right)-1\right][19]$.

\section{Study design}

Patients were enrolled within the first 24 hours from the onset of septic shock after having established normovolemia (PAOP $=12$ to $18 \mathrm{~mm} \mathrm{Hg}$ and $\mathrm{CVP}=8$ to $12 \mathrm{~mm} \mathrm{Hg}$ ) [18] and an MAP of at least $65 \mathrm{~mm} \mathrm{Hg}$ using norepinephrine, if needed. Packed red blood cells were transfused when hemoglobin concentrations decreased to below $7 \mathrm{~g} / \mathrm{dL}$ [18] or if the patient exhibited clinical signs of inadequate systemic oxygen supply. Forty patients were randomly allocated to the treatment with either (a) intravenous levosimendan $0.2 \mu \mathrm{g} / \mathrm{kg}$ per minute (without a loading bolus dose) for 24 hours or (b) intravenous dobutamine $5 \mu \mathrm{g} / \mathrm{kg}$ per minute as active comparator $(=$ control) in a double-blinded manner (each $n=20$ ). The consort diagram is presented in Figure 1. Systemic and pulmonary hemodynamic variables, microcirculatory flow variables, blood gases, and norepinephrine requirements were determined at baseline and 24 hours after randomization. After the 24-hour intervention period, study drugs were discontinued and open-label dobutamine was started if judged as appropriate by the attending ICU physician.

\section{Statistical analysis}

An $a$ priori analysis of sample size revealed that at least 17 patients per group were required to demonstrate a minimum difference of $20 \%$ between groups in the

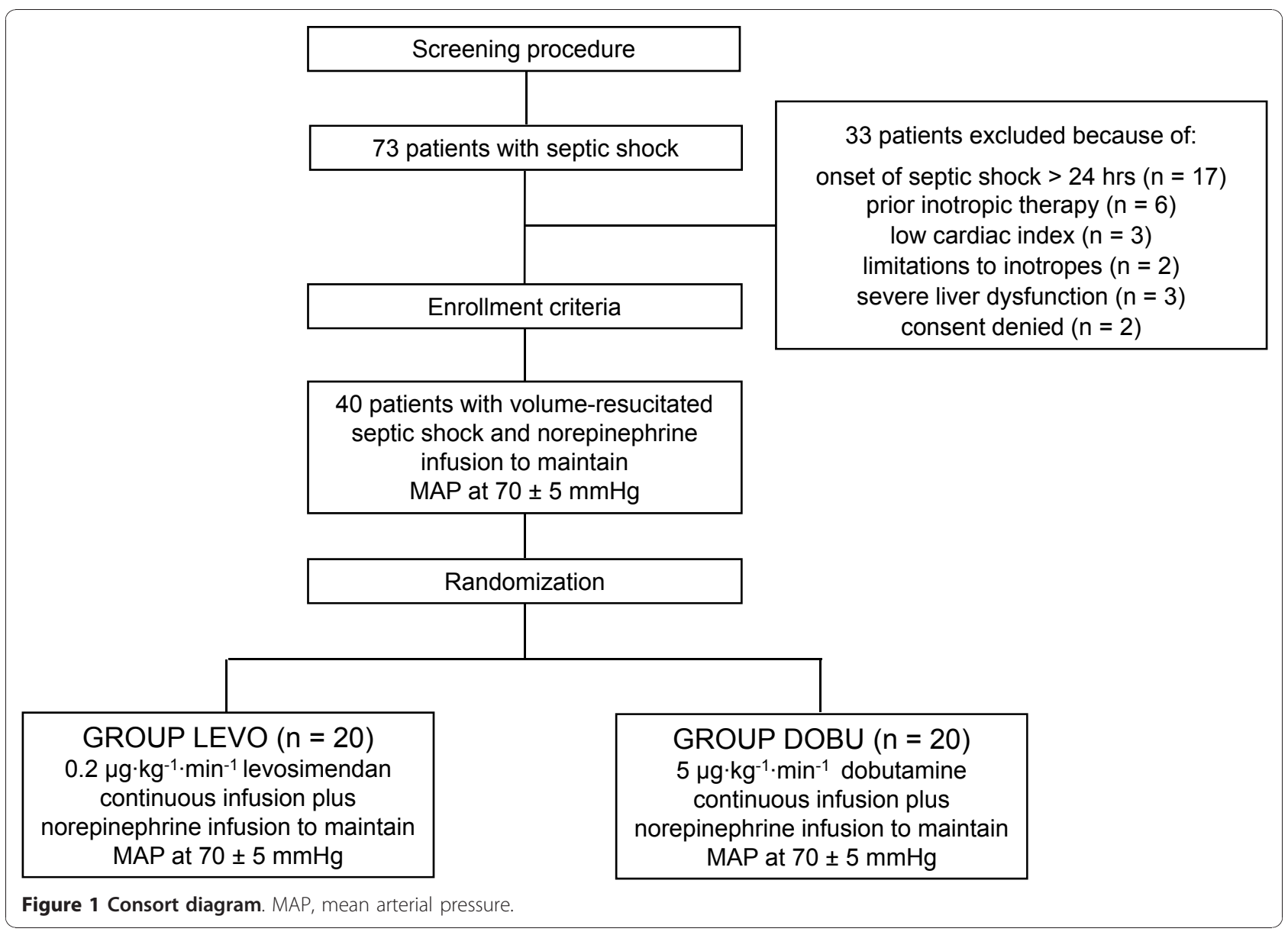


primary endpoint with an estimated standard deviation of $20 \%$, a test power of $80 \%$, and an alpha error of $5 \%$. Data are expressed as median (25th; 75th percentile) if not otherwise specified. Sigma Stat 3.10 software (Systat Software, Inc., Chicago, IL, USA) was used for statistical analysis. Baseline and demographic data were compared with a Mann-Whitney rank sum test or chi-square test, as appropriate. Microvascular and hemodynamic variables were analyzed with a Mann-Whitney rank sum test. The correlation between systemic and microcirculatory flow variables within each group was tested by means of Spearman rank order correlation. A $P$ value of less than 0.05 was considered statistically significant for all tests.

\section{Results}

\section{Demographic data}

Baseline characteristics, including age, gender, body weight, and origin, as well as onset time of septic shock, Simplified Acute Physiology Score II (SAPS II), and mortality were not different among groups (Table 1). In addition, there was no significant difference between groups at baseline in any of the investigated hemodynamic or microcirculatory variables.

\section{Hemodynamic and oxygen transport variables}

Systemic and pulmonary hemodynamic variables were comparable between groups. $\mathrm{SvO}_{2}$ and arterial $\mathrm{pH}$ tended to be higher whereas NE requirements tended to be lower in the levosimendan group (Table 2). However, these differences did not reach statistical significance.

\section{Concomitant therapies}

Activated protein $\mathrm{C}$ was administered in five patients in the control group and in four patients in the levosimendan group. Three patients in each group required continuous renal replacement therapy during the study period. These treatments were equally distributed among groups (each $P$ value of greater than 0.05 ).

\section{Microcirculatory variables}

Microcirculatory data are presented in Figures 2, 3 and 4. MFIm and MFIs were significantly higher (MFIm $3.0[3.0 ; 3.0]$ versus $2.9[2.8 ; 3.0] ; P=0.02$; MFIs 2.9 $[2.9 ; 3.0]$ versus $2.7[2.3 ; 2.8] ; P<0.001)$ and heterogenity index was lower after 24 hours of treatment with levosimendan versus dobutamine (heterogenity index 0.63 [0.44;0.87] versus 0.26 [0.12;0.51]; $P=0.001$ ). Since baseline data varied (non-significantly) among groups, relative changes from baseline were calculated and compared between groups. Relative increases from baseline of MFIs, MFIm, PPV, and PVD (that is, dMFIs, dMFIm, dPPV, and dPVD) were significantly higher in the levosimendan group (Figure 3 and 4). In addition, the heterogeneity index decreased relative to baseline only in the levosimendan group. Correlation analyses (that is, $\mathrm{DO}_{2} \mathrm{I}$ and $\mathrm{CI}$ versus MFIm and MFIs in each group) revealed no statistically significant results (each $P>0.05$; Figure 5).

\section{Discussion}

The major finding of the present study is that levosimendan improved microvascular perfusion in patients with septic shock, as indicated by increases in MFIs, MFIm, and PVD. Notably, this improvement was related to enhanced convection rather than changes in diffusion distance.

The role of levosimendan in severe sepsis or septic shock is still not fully elucidated and remains controversial [12,14-16,20-26]. However, there is increasing evidence that under normovolemic conditions, continuous infusion with levosimendan attenuates septic myocardial dysfunction $[6-10,27,28]$ without aggravating hemodynamic instability. In harmony with previous reports [6-10,27,28], levosimendan did not influence arterial blood pressure or NE requirements in the present study. Furthermore, we noticed neither an increase in heart rate nor new onsets of tachyarrhythmias following levosimendan infusion in our fluid-resuscitated septic shock

Table 1 Characteristics of the study patients

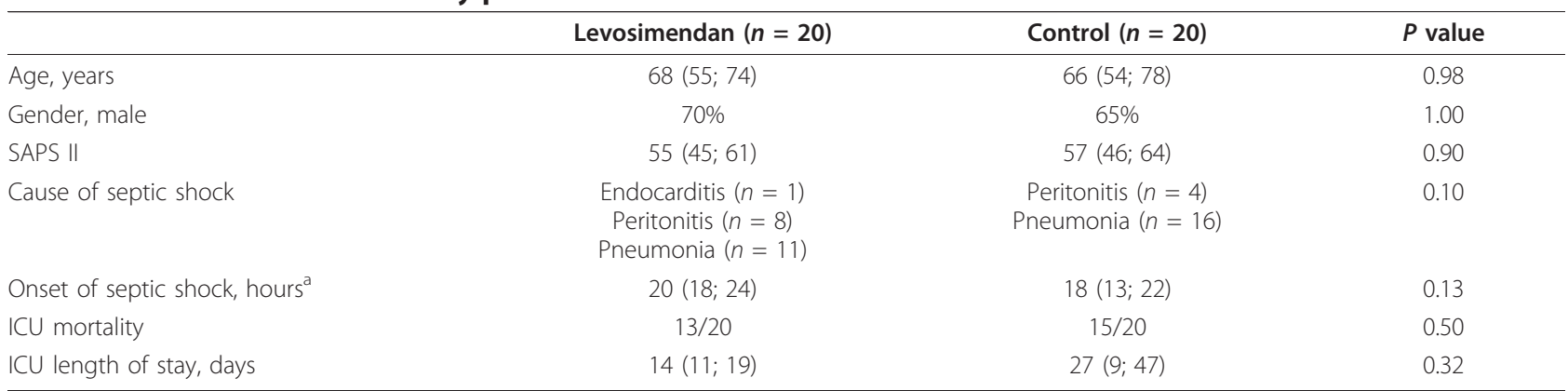

Data are presented as median (25th; 75th percentile). Control, dobutamine $5 \mu \mathrm{g} / \mathrm{kg}$ per minute. ${ }^{\mathrm{a}}$ Onset of septic shock defines the time elapsed from the onset of septic shock until administration of study drug. ICU, intensive care unit; SAPS II, Simplified Acute Physiology Score II. 
Table 2 Hemodynamic and metabolic data of the study patients

\begin{tabular}{|c|c|c|c|c|}
\hline & & Levosimendan $(n=20)$ & Control $(n=20)$ & $P$ value \\
\hline \multirow[t]{2}{*}{$\mathrm{Cl}, \mathrm{L} / \mathrm{min}$ per $\mathrm{m}^{2}$} & $\mathrm{BL}$ & $3.6(2.9 ; 4.3)$ & $3.9(2.9 ; 4.6)$ & 0.70 \\
\hline & 24 hours & $4.1(3.5 ; 5.1)^{a}$ & $4.1(3.3 ; 5.0)$ & 0.66 \\
\hline \multirow[t]{2}{*}{$\mathrm{HR}$, beats per minute } & $B L$ & $96(87 ; 107)$ & $95(90 ; 106)$ & 0.75 \\
\hline & 24 hours & $94(86 ; 104)$ & $98(87 ; 114)$ & 0.36 \\
\hline \multirow[t]{2}{*}{ MAP, $\mathrm{mm} \mathrm{Hg}$} & $\mathrm{BL}$ & $70(67 ; 72)$ & $72(70 ; 74)$ & 0.11 \\
\hline & 24 hours & $72(69 ; 73)$ & $73(70 ; 75)$ & 0.13 \\
\hline \multirow[t]{2}{*}{ PAOP, $\mathrm{mm} \mathrm{Hg}$} & $B L$ & $18(15 ; 18)$ & $19(15 ; 21)$ & 0.25 \\
\hline & 24 hours & $16(16 ; 18)$ & $17(14 ; 21)$ & 0.52 \\
\hline \multirow[t]{2}{*}{ RAP, mm Hg } & $B \mathrm{~L}$ & $14(11 ; 16)$ & $14(11 ; 16)$ & 0.81 \\
\hline & 24 hours & $13(11 ; 14)$ & $14(10 ; 18)$ & 0.27 \\
\hline \multirow[t]{2}{*}{ LVSWI, $g \cdot m / m^{2}$} & $B L$ & $26(21 ; 32)$ & $30(25 ; 36)$ & 0.13 \\
\hline & 24 hours & $34(29 ; 38)^{\mathrm{a}}$ & $32(29 ; 38)$ & 0.56 \\
\hline \multirow[t]{2}{*}{$\mathrm{DO}_{2} \mathrm{l}, \mathrm{mL} / \mathrm{min}$ per $\mathrm{m}^{2}$} & $B \mathrm{~L}$ & $431(363 ; 531)$ & $492(393 ; 550)$ & 0.27 \\
\hline & 24 hours & $512(438 ; 612)$ & $519(436 ; 593)$ & 0.93 \\
\hline \multirow[t]{2}{*}{$\mathrm{VO}_{2} \mathrm{l}, \mathrm{mL} / \mathrm{min}$ per $\mathrm{m}^{2}$} & $B L$ & $111(93 ; 151)$ & $126(112 ; 153)$ & 0.18 \\
\hline & 24 hours & $127(107 ; 144)$ & $149(110 ; 178)$ & 0.24 \\
\hline \multirow{2}{*}{$\mathrm{O}_{2}$-ER, percentage } & $\mathrm{BL}$ & $28(24 ; 32)$ & $29(22 ; 34)$ & 0.99 \\
\hline & 24 hours & $25(20 ; 27)^{a}$ & $27(21 ; 36)$ & 0.17 \\
\hline \multirow[t]{2}{*}{$\mathrm{SaO}_{2}$, percentage } & $B \mathrm{~L}$ & $98(96 ; 99)$ & $98(95 ; 99)$ & 0.99 \\
\hline & 24 hours & $99(99 ; 99)^{a}$ & $99(94 ; 99)$ & 0.02 \\
\hline \multirow[t]{2}{*}{$\mathrm{PaCO}_{2}, \mathrm{~mm} \mathrm{Hg}$} & $B L$ & $45(41 ; 50)$ & $41(37 ; 51)$ & 0.35 \\
\hline & 24 hours & $41(37 ; 44)$ & $41(36 ; 49)$ & 0.42 \\
\hline \multirow[t]{2}{*}{$\mathrm{SvO}_{2}$, percentage } & $B \mathrm{~L}$ & $72(66 ; 75)$ & $70(66 ; 78)$ & 0.95 \\
\hline & 24 hours & $77(74 ; 81)^{a}$ & $71(62 ; 78)$ & 0.06 \\
\hline \multirow[t]{2}{*}{$\mathrm{Hb}_{a}, \mathrm{~g} / \mathrm{dL}$} & $\mathrm{BL}$ & $8.6(8.0 ; 8.9)$ & $9.0(8.0 ; 9.6)$ & 0.96 \\
\hline & 24 hours & $8.5(8.0 ; 8.9)$ & $8.8(8.0 ; 9.3)$ & 0.42 \\
\hline \multirow[t]{2}{*}{$\mathrm{pH}_{\mathrm{a}},-\log _{10} \mathrm{C}\left(\mathrm{H}^{+}\right)$} & $\mathrm{BL}$ & $7.29(7.25 ; 7.34)$ & $7.28(7.25 ; 7.38)$ & 0.87 \\
\hline & 24 hours & $7.38(7.29 ; 7.40)^{\mathrm{a}}$ & $7.32(7.23 ; 7.37)$ & 0.06 \\
\hline \multirow[t]{2}{*}{$\mathrm{aBE}, \mathrm{mmol} / \mathrm{L}$} & $B \mathrm{~L}$ & $-4.9(-6.9 ;-2.5)$ & $-3.8(-9.0 ; 0.0)$ & 0.72 \\
\hline & 24 hours & $-2.9(-5.0 ;-0.6)$ & $-3.8(-8.9 ; 1.8)$ & 0.74 \\
\hline \multirow[t]{2}{*}{ Lactate, mmol/L } & $B \mathrm{~L}$ & $2.3(1.3 ; 2.9)$ & $1.9(1.3 ; 2.9)$ & 0.72 \\
\hline & 24 hours & $1.9(1.2 ; 2.5)$ & $1.6(1.3 ; 3.6)$ & 0.61 \\
\hline \multirow[t]{2}{*}{ Fluid input, $\mathrm{mL} / 24$ hours } & $B \mathrm{~L}$ & NA & NA & NA \\
\hline & 24 hours & $5,700(4,700 ; 6,050)$ & $4,850(4,150 ; 5,200)$ & 0.01 \\
\hline \multirow[t]{2}{*}{ NE dosage, $\mu \mathrm{g} / \mathrm{kg}$ per min } & $B L$ & $0.4(0.2 ; 0.9)$ & $0.4(0.3 ; 0.7)$ & 0.72 \\
\hline & 24 hours & $0.3(0.1 ; 0.9)$ & $0.4(0.3 ; 1.1)$ & 0.10 \\
\hline
\end{tabular}

Data are presented as median (25th; 75th percentile). Control, dobutamine $5 \mu \mathrm{g} / \mathrm{kg}$ per minute. ${ }^{\text {a }} P<0.05$ versus baseline (BL) within groups. aBE, arterial base excess; $\mathrm{Cl}$, cardiac index; $\mathrm{DO}_{2}$, systemic oxygen delivery index; $\mathrm{Hb}_{3}$, arterial hemoglobin concentration; HR, heart rate; LVSWI, left ventricular stroke work index; MAP, mean arterial pressure; $\mathrm{NA}$, not applicable; $\mathrm{NE}$, norepinephrine; $\mathrm{O}_{2}-\mathrm{ER}$, oxygen extraction ratio; $\mathrm{PaCO} \mathrm{C}_{2}$, arterial partial pressure of carbon dioxide; $\mathrm{PAOP}$, pulmonary arterial occlusion pressure; $\mathrm{pH}_{\mathrm{a}}$, arterial potentia hydrogenii; $\mathrm{RAP}$, right atrial pressure; $\mathrm{SaO}_{2}$, arterial oxygen saturation; $\mathrm{SvO}_{2}$, mixed-venous oxygen saturation; $\mathrm{VO}_{2} \mathrm{l}$, oxygen consumption index.

patients. These findings strengthen the assumption that under normovolemic conditions, the decrease in vascular resistance (owing to the opening of $\mathrm{K}_{\mathrm{ATP}}$ channels) following levosimendan infusion may be compensated by a simultaneous increase in myocardial contractility.

The hypothesis that constituted the basis of our study was that (besides the effects on myocardial contractility) levosimendan - by its vasodilatory effects - improves microcirculatory blood flow by increasing the driving pressure of blood flow at the entrance of the microcirculation
[3]. In fact, we noticed that levosimendan improved sublingual microcirculation, as indicated by significant increases in MFIs, MFIm, dMFIs, and dMFIm. In addition, we observed an increase in dPVD following levosimendan infusion, further indicating an improvement of the microcirculation. We focused our investigation on the effects of the study drug on MFI of the small and medium vessels since alterations in such microvessels are typically associated with organ dysfunction and - if persisting - poor outcome [1-5]. 

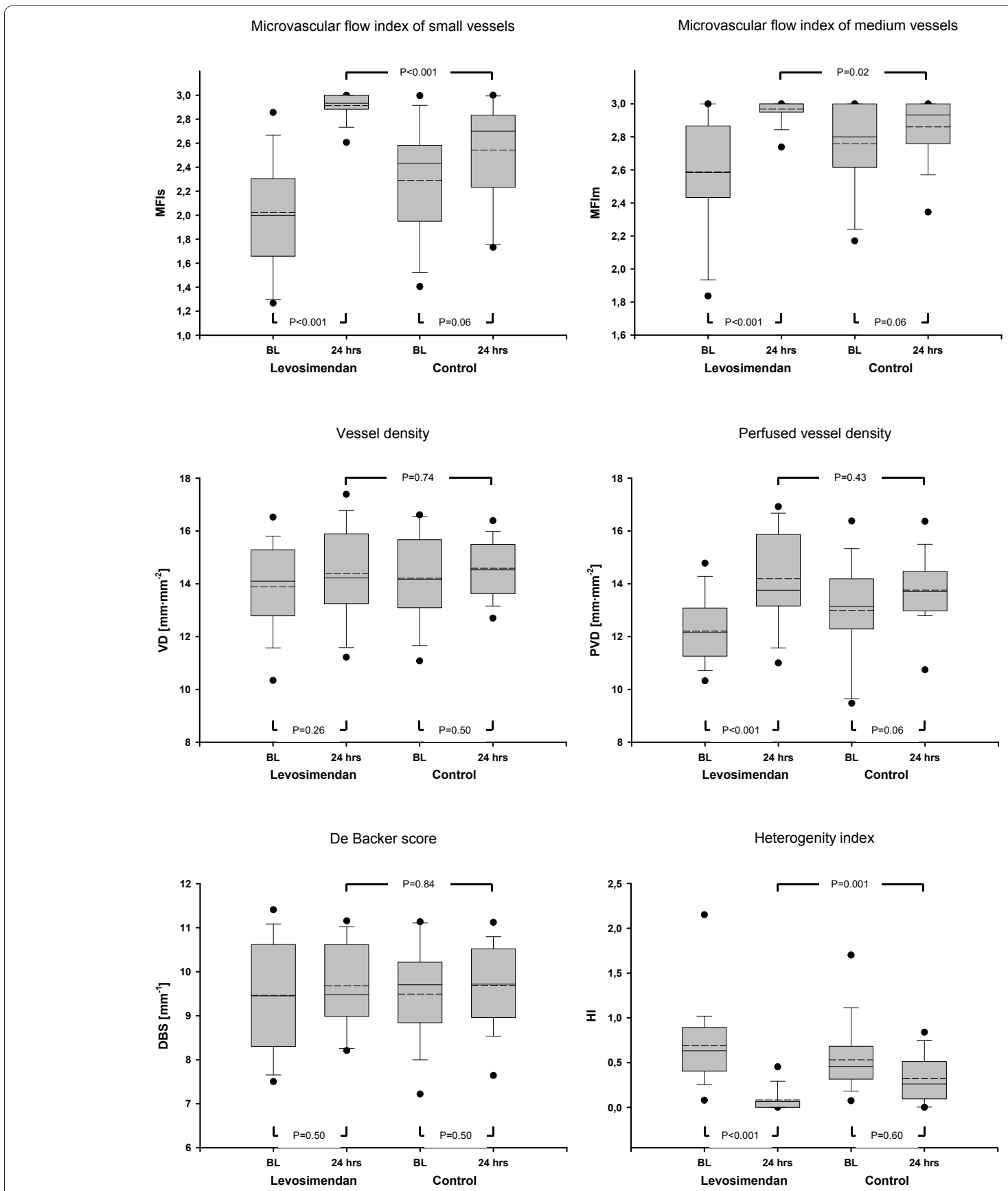

Figure 2 Absolute changes in microcirculatory variables. BL, baseline; DBS, De Backer score; HI, heterogenity index; MFIm, microvascular flow index of medium vessels ( $\varnothing 20$ to $50 \mu \mathrm{m}$ ); MFls, microvascular flow index of small vessels $(\varnothing<20 \mu \mathrm{m}$ ); PVD, perfused vessel density; VD, vessel density.

Whereas the increases in MFI suggest that levosimendan ameliorated blood flow within the perfused vessels, the increase in PPV with a concomitant decrease in heterogeneity index indicates a recruitment of non-perfused vessels and hence a reduction of the diffusion distance between capillaries. In light of these findings, it is most likely that levosimendan enhanced both convection and diffusion, thereby improving oxygen delivery at the level of the microcirculation.

Although the increases in $\mathrm{SvO}_{2}$ and $\mathrm{pH}$ noticed in the levosimendan group may further indicate an improvement in microcirculatory blood flow, it has to be considered that an improvement in pulmonary function (increase in $\mathrm{PaO}_{2}$ [arterial oxygen partial pressure] and 


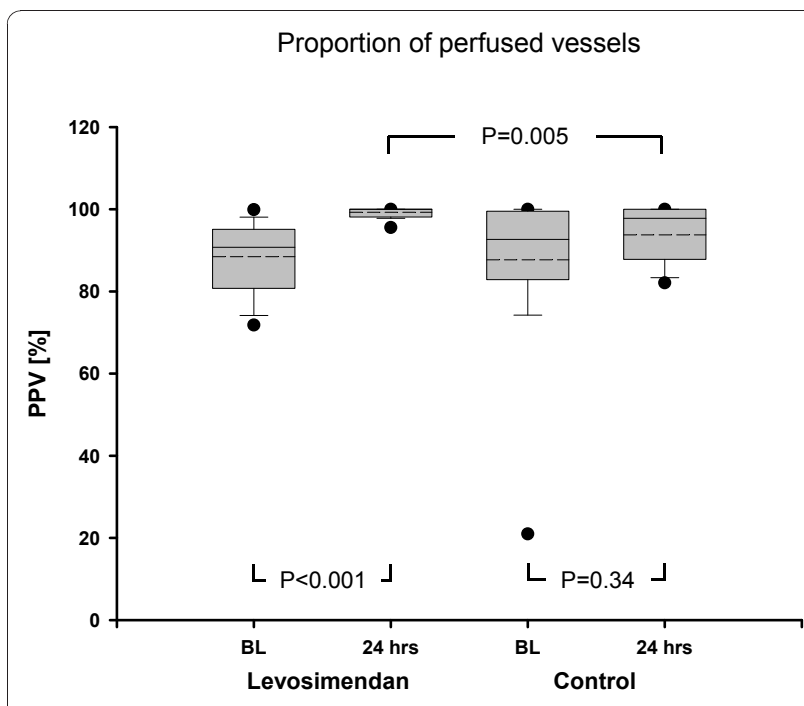

Relative changes in proportion of perfused vessels

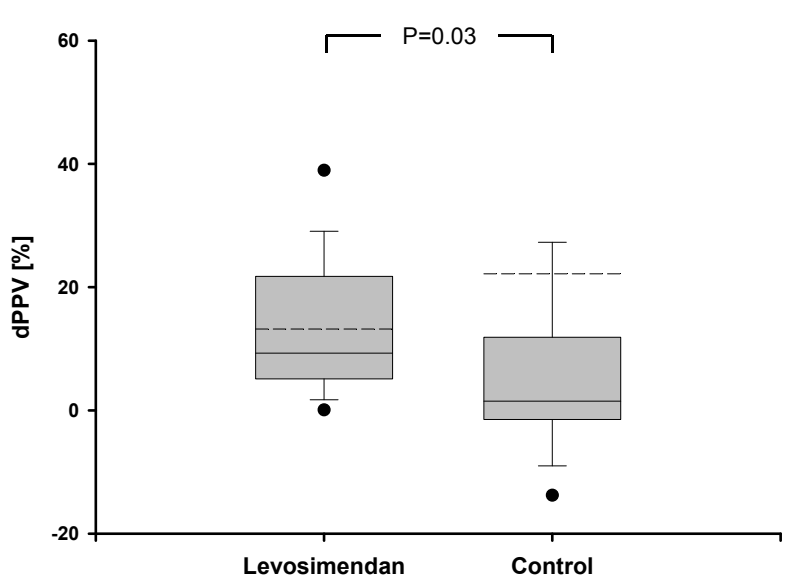

Figure 3 Absolute and relative changes in microcirculatory variables. $\mathrm{BL}$, baseline; $\mathrm{dPPV}$, relative changes in proportion of perfused vessels; PPV, proportion of perfused vessels.

$\mathrm{SaO}_{2}$ [arterial oxygen saturation] with a concomitant decrease in $\mathrm{PaCO}_{2}$ [arterial partial pressure of carbon dioxide]) following levosimendan administration might have contributed to these changes. This assumption is supported by recent experimental and clinical studies showing that levosimendan in fact improves pulmonary function and gas exchange $[8,12,14,20,25,26]$. However, it may well be that levosimendan (secondary to its vasodilatatory properties) has promoted microvascular shunting and thereby increased venous oxygen saturation.

Our results are in line with those of an experimental study by Schwarte and colleagues [29], who reported that levosimendan selectively increases gastric microvascular mucosal oxygenation in dogs. Whereas a previous experimental study [30] showed that levosimendan improved microvascular oxygenation in experimental sepsis, our study demonstrates for the first time that levosimendan selectively increases microvascular blood flow in the clinical setting. However, the present study design does not allow us to exclude whether non-hemodynamic effects of levosimendan, such as the ability to decrease cytokine synthesis, plasma levels of endothelin1, ICAM-1 (intercellular adhesion molecule-1), and VCAM-1 (vascular cell adhesion molecule-1) [12,13,26], might have contributed to the improvement of microcirculation.

Notably, the lack of modifications in the proportion of perfused vessels observed in the control group (in which the patients were treated with dobutamine as an active comparator at a dose of $5 \mu \mathrm{g} / \mathrm{kg}$ per minute) varies from the study of De Backer and colleagues [2], who reported that the same dose of dobutamine increased microvascular density and the proportion of perfused vessels, a finding that clearly indicated an improved microcirculation in a series of septic shock patients. However, despite the use of an equivalent dobutamine dose [2], there is a marked difference in the study designs in terms of time frame. In this regard, the previously reported short-term response to dobutamine after 2 hours [2] was outside the scope of our investigation. A likely explanation might be related to the fact that we performed microcirculatory evaluation at the end of 24 hours of drug infusion in progressed septic shock. It is well recognized that, owing to adrenergic receptor and signaling abnormalities, the efficacy of catecholamines often gradually decreases over time [31]. This may account for the attenuated hemodynamic effects of $5 \mu \mathrm{g} / \mathrm{kg}$ per minute dobutamine infusion in patients with severe septic shock $[7,32,33]$ in comparison with patients with less severe sepsis [34]. On this basis, it is conceivable that microvessels may reach a near maximal vasodilation in the early phase of dobutamine administration lasting for a brief period $[2,32,35]$, whereas after 24 hours, the effects of $5 \mu \mathrm{g} / \mathrm{kg}$ per minute of dobutamine on the microcirculation are attenuated. In this light, our findings support the hypothesis formulated by De Backer and colleagues [2] that stronger vasodilatory compounds, such as levosimendan, may be more effective than dobutamine for improving microcirculatory blood flow. However, these postulated advantages of levosimendan remain to be further elucidated in larger clinical trials.

The present study has some limitations that we would like to acknowledge. First, we administered a fixed dose of $5 \mu \mathrm{g} / \mathrm{kg}$ per minute of dobutamine and cannot exclude the possibility that a higher dose would have resulted in different findings. However, it is important to note that our intention was not to perform a direct comparison between dobutamine and levosimendan but 


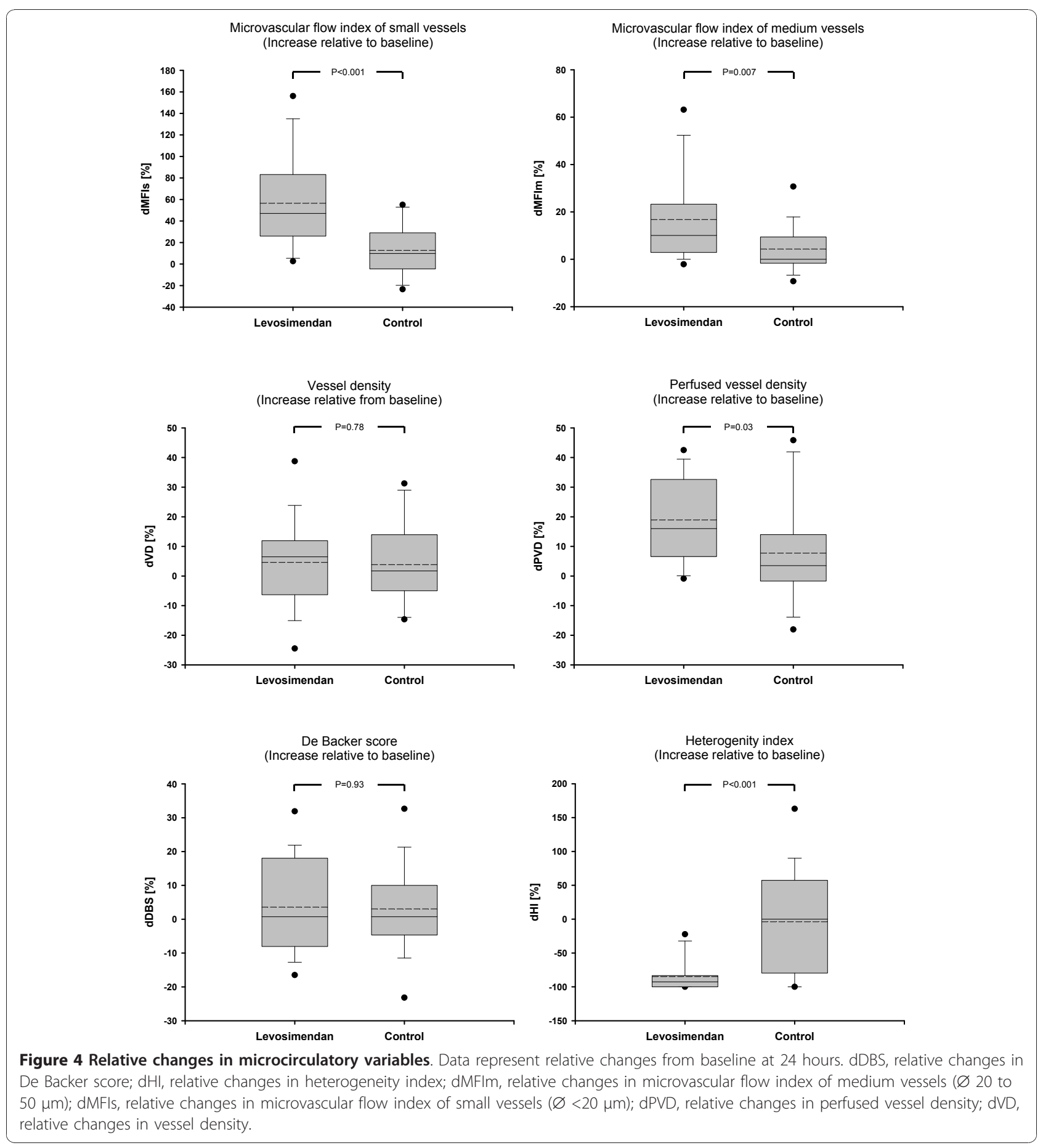

to use the selected dobutamine dose as an 'active comparator' to facilitate blinding of the study drugs. Indeed, randomization of levosimendan versus placebo would have unmasked group allocation because of the strong hemodynamic effects of levosimendan. Second, in the present study, the improvement in microvascular perfusion was independent from changes in CI. However, it is also possible that these variables might correlate in a way that is more complex than the linear correlation of percentage changes in CI and oxygen delivery. Therefore, a possible correlation should be clarified in future larger studies. Third, owing to the lack of investigation of specific variables, we cannot conclude whether anti-ischemic and anti-inflammatory effects, as well as effects at the cellular level [13], have contributed to the improved microcirculatory blood flow with 


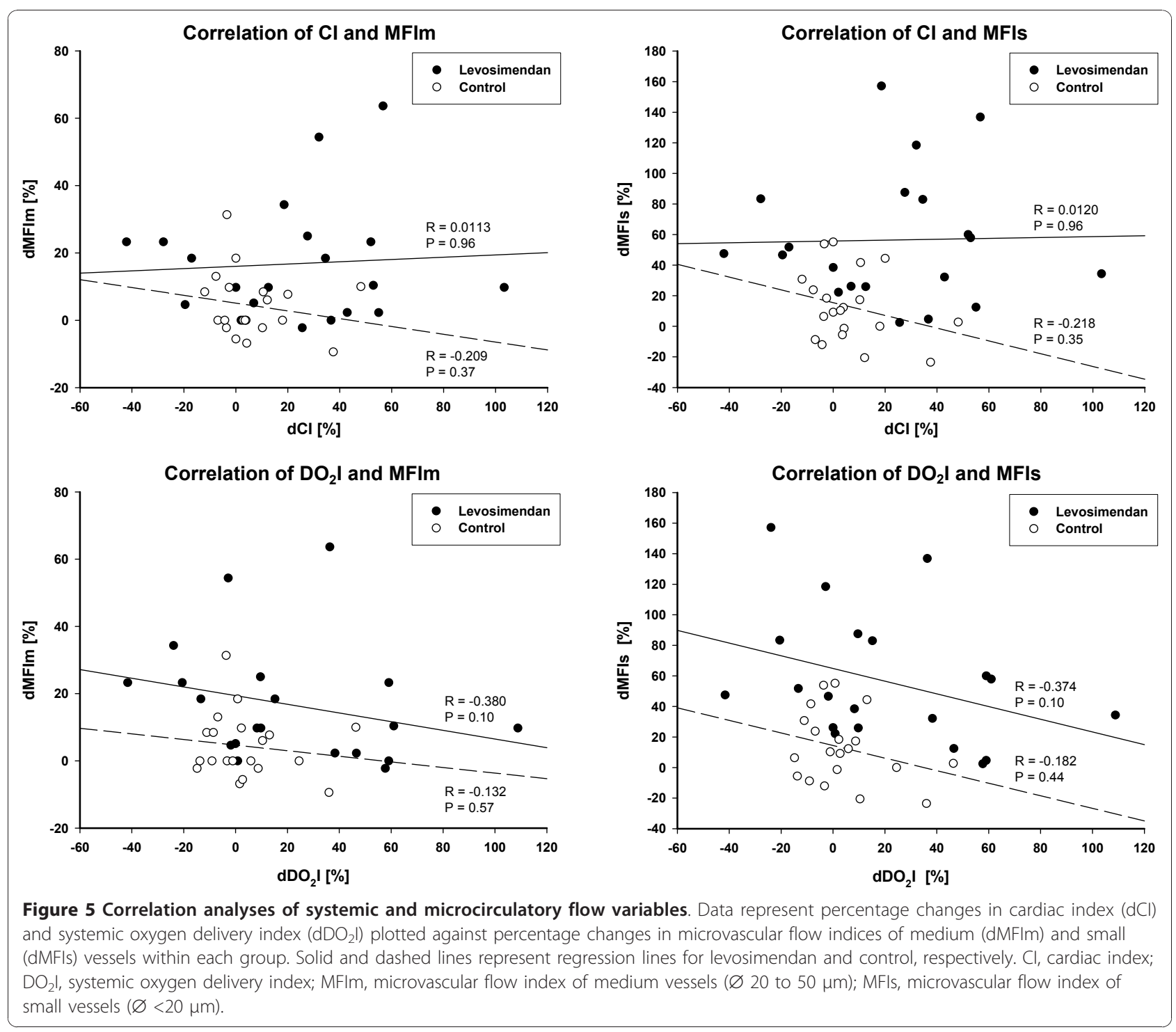

levosimendan. In addition, we investigated the changes in microvascular perfusion of the sublingual mucosa which might not be representative of alterations in other tissues [1]. Furthermore, owing to the pharmacokinetic characteristics of the study drug, the present study protocol required a relatively long time interval (24 hours of drug infusion) that does not allow the exclusion of a direct time-dependent effect unrelated to the specific agent. Finally, we have chosen changes in MFIs as the primary endpoint of this study. Since we investigated only a small number of septic shock patients treated over a relative brief period, the risk of positive results in a study with numerous secondary variables has to be taken into account. Thus, caution should be exercised in interpreting the results of the secondary outcome variables.

\section{Conclusions}

This is the first prospective, randomized clinical study investigating the effects of levosimendan on sublingual microcirculation in patients with septic shock. Our results demonstrate that levosimendan at $0.2 \mu \mathrm{g} / \mathrm{kg}$ per minute (when compared with a standard dose of $5 \mu \mathrm{g} /$ $\mathrm{kg}$ per minute of dobutamine) improves sublingual microcirculatory blood flow in volume-resuscitated septic shock patients and that this effect was not correlated with changes in systemic flow variables.

\section{Key messages}

- Levosimendan improves sublingual microcirculatory blood flow in volume-resuscitated septic shock patients. 
- Levosimendan enhances convection and improves diffusion, thereby improving oxygen delivery at the level of the microcirculation.

- Levosimendan at $0.2 \mu \mathrm{g} / \mathrm{kg}$ per minute may be more effective than a standard dose of $5 \mu \mathrm{g} / \mathrm{kg}$ per minute of dobutamine for improving microcirculatory blood flow.

- Under normovolemic conditions, levosimendan administration did not influence arterial blood pressure or norepinephrine requirements.

\begin{abstract}
Abbreviations
$\mathrm{Cl}$ : cardiac index; CVP: central venous pressure; dMFIm: relative increases of microvascular flow index of medium vessels; dMFIs: relative increases of microvascular flow index of small vessels; $\mathrm{DO}_{2}$ l: systemic oxygen delivery index; dPVD: relative increase in perfused vessel density; ICU: intensive care unit; $K_{\text {ATP: }}$ ATP-dependent potassium; MAP: mean arterial pressure; MFIm: microvascular flow index of medium vessels; MFIs: microvascular flow index of small vessels; NE: norepinephrine; PAOP: pulmonary arterial occlusion pressure; PPV: proportion of perfused vessels; PVD: perfused vessel density; SDF: sidestream dark-field; $\mathrm{SVO}_{2}$ : mixed-venous oxygen saturation.
\end{abstract}

\section{Acknowledgements}

The authors wish to thank Maria Cristina Marini, Carmela Disanto, Elisa Alessandri, Amalia Laderchi, Tiziana Bria, Laura Mancini, Daniela Auricchio, Anna Sabani, and Tommaso Di leso of the Department of Anesthesiology and Intensive Care of the University of Rome 'La Sapienza' for their contribution to the study.

\section{Author details}

${ }^{1}$ Department of Anesthesiology and Intensive Care, University of Rome, 'La Sapienza', Viale del Policlinico 155, Rome 00161, Italy. ${ }^{2}$ Department of Neuroscience-Anesthesia and Intensive Care Unit, Università Politecnica delle Marche, Via Tronto 10, Torrette di Ancona 60020, Italy. ${ }^{3}$ Department of Anesthesiology and Intensive Care, University Hospital of Muenster, AlbertSchweitzer-Str. 33, Muenster 48149, Germany. ${ }^{4}$ Department of Anesthesia and Intensive Care, Università Vita-Salute San Raffaele, Via Olgettina 60, Milan 20132, Italy. ${ }^{5}$ Hôpital de Bicêtre, Service of Medical Intensive Care, Centre Hospitalier de Bicêtre, rue du Général Leclerc 78, Le Kremlin-Bicêtre 94270, France. ${ }^{6}$ Department of Translational Physiology, Academic Medical Center, University of Amsterdam, Meibergdreef 9, Amsterdam 1105 AZ, The Netherlands. ${ }^{7}$ Department of Intensive Care, Erasmus MC, University Medical Center Rotterdam, 's-Gravendijkwal 230, Rotterdam 3015 CE, The Netherlands.

\section{Authors' contributions}

AM and MW planned the study, were responsible for its design and coordination, and drafted the manuscript. J-LT and GL participated in the study design and helped to draft the manuscript. CE, ML, SR, and HVA participated in the design of the study, performed the statistical analysis, and helped to draft the manuscript. AO, VC, AD, P Pelaia, and $\mathrm{Cl}$ analyzed SDF images and helped to draft the manuscript. P Pietropaoli participated in the study design, helped to draft the manuscript, and obtained funding. All authors read and approved the final manuscript.

\section{Competing interests}

The authors declare that they have no competing interests.

Received: 13 July 2010 Revised: 30 September 2010 Accepted: 23 December 2010 Published: 23 December 2010

\section{References}

1. Trzeciak S, Cinel I, Phillip Dellinger R, Shapiro NI, Arnold RC, Parrillo JE, Hollenberg SM, Microcirculatory Alterations in Resuscitation and Shock (MARS) Investigators: Resuscitating the microcirculation in sepsis: the central role of nitric oxide, emerging concepts for novel therapies, and challenges for clinical trials. Acad Emerg Med 2008, 15:399-413.
2. De Backer D, Creteur J, Dubois MJ, Sakr Y, Koch M, Verdant C, Vincent JL: The effects of dobutamine on microcirculatory alterations in patients with septic shock are independent of its systemic effects. Crit Care Med 2006, 34:403-408.

3. Buwalda M, Ince C: Opening the microcirculation: can vasodilators be useful in sepsis? Intensive Care Med 2002, 28:1208-1217.

4. Spronk PE, Ince C, Gardien MJ, Mathura KR, Oudemans-van Straaten HM, Zandstra DF: Nitroglycerin in septic shock after intravascular volume resuscitation. Lancet 2002, 360:1395-1396.

5. Boerma EC, Koopmans M, Konijn A, Kaiferova K, Bakker AJ, van Roon EN, Buter H, Bruins N, Egbers PH, Gerritsen RT, Koetsier PM, Kingma WP, Kuiper MA, Ince C: Effects of nitroglycerin on sublingual microcirculatory blood flow in patients with severe sepsis/septic shock after a strict resuscitation protocol: a double-blind randomized placebo controlled trial. Crit Care Med 2010, 38:93-100.

6. Noto A, Giacomini M, Palandi A, Stabile L, Reali-Forster C, lapichino G. Levosimendan in septic cardiac failure. Intensive Care Med 2005, 31:164-165.

7. Morelli A, De Castro S, Teboul JL, Singer M, Rocco M, Conti G, De Luca L, Di Angelantonio E, Orecchioni A, Pandian NG, Pietropaoli P: Effects of levosimendan on systemic and regional hemodynamics in septic myocardial depression. Intensive Care Med 2005, 31:638-644.

8. Morelli A, Teboul JL, Maggiore SM, Vieillard-Baron A, Rocco M, Conti G, De Gaetano A, Picchini U, Orecchioni A, Carbone I, Tritapepe L, Pietropaoli P, Westphal M: Effects of levosimendan on right ventricular afterload in patients with acute respiratory distress syndrome: a pilot study. Crit Care Med 2006, 34:2287-2293.

9. Powell BP, De Keulenaer BL: Levosimendan in septic shock: a case series. Br J Anaesth 2007, 99:447-448.

10. Pinto BB, Rheberg S, Ertmer C, Westphal M: Role of levosimendan in sepsis and septic shock. Curr Opin Anaesthesiol 2008, 21:168-177.

11. Toller WG, Stranz C: Levosimendan, a new inotropic and vasodilator agent. Anesthesiology 2006, 104:556-569.

12. Scheiermann $P$, Ahluwalia D, Hoegl S, Dolfen A, Revermann M, Zwissler $B$, Muhl H, Boost KA, Hofstetter C: Effects of intravenous and inhaled levosimendan in severe rodent sepsis. Intensive Care Med 2009, 35:1412-1419.

13. Antoniades C, Tousoulis D, Koumallos N, Marinou K, Stefanadis C: Levosimendan: beyond its simple inotropic effect in heart failure. Pharmacol Ther 2007, 114:184-197.

14. Rehberg S, Ertmer C, Vincent JL, Spiegel HU, Köhler G, Erren M, Lange M, Morelli A, Seisel J, Su F, Van Aken H, Traber DL, Westphal M: Effects of combined arginine vasopressin and levosimendan on organ function in ovine septic shock. Crit Care Med 2010, 38:2016-2023.

15. Dubin A, Murias G, Sottile JP, Pozo MO, Barán M, Edul VS, Canales HS, Etcheverry G, Maskin B, Estenssoro E: Effects of levosimendan and dobutamine in experimental acute endotoxemia: a preliminary controlled study. Intensive Care Med 2007, 33:485-494.

16. García-Septiem J, Lorente JA, Delgado MA, de Paula M, Nin N, Moscoso A Sánchez-Ferrer A, Perez-Vizcaino F, Esteban A: Levosimendan increases portal blood flow and attenuates intestinal intramucosal acidosis in experimental septic shock. Shock 2010, 34:275-280.

17. De Backer D, Hollenberg S, Boerma C, Goedhart P, Büchele G, OspinaTascon G, Dobbe I, Ince C: How to evaluate the microcirculation? Report of a round table conference. Crit Care 2007, 11:R101-111.

18. Dellinger RP, Levy MM, Carlet JM, Bion J, Parker MM, Jaeschke R, Reinhart K, Angus DC, Brun-Buisson C, Beale R, Calandra T, Dhainaut JF, Gerlach H, Harvey M, Marini JJ, Marshall J, Ranieri M, Ramsay G, Sevransky J, Thompson BT, Townsend S, Vender JS, Zimmerman JL, Vincent JL, International Surviving Sepsis Campaign Guidelines Committee; American Association of Critical-Care Nurses; American College of Chest Physicians; American College of Emergency Physicians; Canadian Critical Care Society; European Society of Clinical Microbiology and Infectious Diseases, et al: Surviving Sepsis Campaign: international guidelines for management of severe sepsis and septic shock 2008. Crit Care Med 2008, 36:296-327.

19. Kaiser L: Adjusting for baseline: change or percentage change. Stat Med 1989, 8:1183-1190

20. Erbüyün $K$, Vatansever $S$, Tok D, Ok G, Türköz E, Aydede H, Erhan Y, Tekin I: Effects of levosimendan and dobutamine on experimental acute lung injury in rats. Acta Histochem 2009, 111:404-414. 
21. Barraud D, Faivre V, Damy T, Welschbillig S, Gayat E, Heymes C, Payen D, Shah AM, Mebazaa A: Levosimendan restores both systolic and diastolic cardiac performance in lipopolysaccharide-treated rabbits: comparison with dobutamine and milrinone. Crit Care Med 2007, 35:1376-1382.

22. Cunha-Goncalves D, Perez-de-Sa V, Dahm P, Grins E, Thörne J, Blomquist S: Cardiovascular effects of levosimendan in the early stages of endotoxemia. Shock 2007, 28:71-77.

23. Dubin A, Maskin B, Murias G, Pozo MO, Sottile JP, Barán M, Edul VS, Canales HS, Estenssoro E: Effects of levosimendan in normodynamic endotoxaemia: a controlled experimental study. Resuscitation 2006, 69:277-286.

24. Faivre V, Kaskos H, Callebert J, Losser MR, Milliez P, Bonnin P, Payen D, Mebazaa A: Cardiac and renal effects of levosimendan, arginine vasopressin, and norepinephrine in lipopolysaccharide-treated rabbits. Anesthesiology 2005, 103:514-521.

25. Oldner A, Konrad D, Weitzberg E, Rudehill A, Rossi P, Wanecek M: Effect of levosimendan a novel inotropic calcium-sensitizing drug, in experimental septic shock. Crit Care Med 2001, 29:2185-2193.

26. Scheiermann P, Ahluwalia D, Hoegl S, Dolfen A, Revermann M, Zwissler B, Muhl H, Boost KA, Hofstetter C: Inhaled levosimendan reduces mortality and release of proinflammatory mediators in a rat model of experimental ventilator-induced lung injury. Crit Care Med 2008, 36:1979-1981.

27. Ramaswamykanive H, Bihari D, Solano TR: Myocardial depression associated with pneumococcal septic shock reversed by levosimendan. Anaesth Intensive Care 2007, 35:409-413.

28. Matejovic M, Krouzecky A, Radej J, Novak I: Successful reversal of resistent hypodynamic septic shock with levosimendan. Acta Anaesthesio/ Scand 2005, 49:127-128.

29. Schwarte LA, Picker O, Bornstein SR, Fournell A, Scheeren TW: Levosimendan is superior to milrinone and dobutamine in selectively increasing microvascular gastric mucosal oxygenation in dogs. Crit Care Med 2005, 33:135-142.

30. Fries M, Ince C, Rossaint R, Bleilevens C, Bickenbach J, Rex S, Mik EG Levosimendan but not norepinephrine improves microvascular oxygenation during experimental septic shock. Crit Care Med 2008, 36:1886-1891

31. Landry DW, Oliver JA: The pathogenesis of vasodilatory shock. N Engl J Med 2001, 345:588-595.

32. Duranteau J, Sitbon P, Teboul JL, Vicaut E, Anguel N, Richard C, Samii K: Effects of epinephrine, norepinephrine or combination of norepinephrine and dobutamine on gastric mucosa in septic shock. Crit Care Med 1999, 27:893-900.

33. Levy B, Nace L, Bollaert PE, Dousset B, Mallie JP, Larcan A: Comparison of systemic and regional effects of dobutamine and dopexamine in norepinephrine-treated septic shock. Intensive Care Med 1999, 25:942-948.

34. Creteur J, De Backer D, Vincent JL: A dobutamine test can disclose hepatosplanchnic hypoperfusion in septic patients. Am J Respir Crit Care Med 1999, 160:839-845

35. Lebuffe G, Levy B, Nevière R, Chagnon JL, Perrigault PF, Duranteau J, Edouard A, Teboul JL, Vallet B: Dobutamine and gastric-to-arterial carbon dioxide gap in severe sepsis without shock. Intensive Care Med 2002, 28:265-271.

\section{doi:10.1186/cc9387}

Cite this article as: Morelli et al.: Levosimendan for resuscitating the microcirculation in patients with septic shock: a randomized controlled study. Critical Care 2010 14:R232.

\section{Submit your next manuscript to BioMed Central and take full advantage of:}

- Convenient online submission

- Thorough peer review

- No space constraints or color figure charges

- Immediate publication on acceptance

- Inclusion in PubMed, CAS, Scopus and Google Scholar

- Research which is freely available for redistribution 